\title{
AS DESIGNAÇÕES PARA CONJUNTIVITE NOS DADOS DO PROJETO ALIB: REVELAÇÕES DIAGERACIONAIS
}

\author{
THE FORMS FOR CONJUNCTIVITIS IN THE ALIB PROJECT: GENERATIONAL \\ REVELATIONS
}

\author{
Marcela Moura Torres Paim \\ Professora da Universidade Federal da Bahia \\ marcelamtpaim@yahoo.com.br
}

\begin{abstract}
RESUMO: Este estudo investiga como a linguagem de indivíduos apresenta marcas linguísticas específicas que constroem, mantêm e projetam a identidade social de faixa etária em inquéritos do Projeto ALiB (Atlas Linguístico do Brasil), a partir da utilização do léxico como característica diageracional dos indivíduos no grupo etário do qual fazem parte. A metodologia empregada consistiu na realização das seguintes etapas: 1) definição da base teórica a ser seguida; 2) escolha e formação do corpus, constituído de inquéritos do Projeto ALiB; 3) análise do corpus a fim de verificar marcas linguísticas transmissoras da construção, projeção e manutenção da identidade social de faixa etária. A análise do corpus permitiu identificar-se a diversidade lexical do português falado no Brasil, com base nos princípios da Geolinguística Pluridimensional em que o registro segue os parâmetros diatópicos e diastráticos.

PALAVRAS-CHAVE: Variação; Identidade social; Faixa etária.
\end{abstract}

ABSTRACT: This paper investigates how the language of individuals presents specific linguistic marks that construct, maintain and project age-group social identity in the questionnaire of the ALiB project, based on the use of the lexicon as a generational factor of individuals within their age-group. The methodology used was based on the performance of the following stages: 1) reading of theoretical texts related to the theme; 2) choice and formation of the corpus, made up of surveys from the ALiB project; 3) analysis of the corpus in order to verify linguistic marks that transmit the construction, projection and maintenance of the age-group social identity. The analysis of the corpus allowed the identification of lexical diversity of the Portuguese language spoken in Brazil, according to the principles of Pluridimensional Geolinguistics, in which the register follows specific parameters. KEYWORDS: Variation; Social identity; Age-group.

\section{INTRODUÇÃO}

No intuito de apresentar uma reflexão sobre a questão da identidade social de faixa etária, utilizou-se a postulada Teoria Social do Discurso por Fairclough em Discurso e Mudança Social (2001). Conforme o referido autor, o discurso é um modo de ação, uma forma com que as pessoas podem agir sobre o mundo e especialmente sobre os outros, como também um modo de representação. Nesse sentido, o discurso é uma prática de significação do mundo, constituindo e construindo o mundo em significado. Tal prática focaliza, dentre os aspectos relativos aos efeitos construtivos, a construção, manutenção e projeção de identidades sociais. Assim, pode-se dizer que o discurso é o local onde as identidades sociais são estabelecidas. 
Mesmo não sendo um tema preferencial para a área, as questões de identidade social têm sido estudadas também no campo da linguística. Com o objetivo de focalizar a perspectiva de identidade social adotada neste trabalho em relação a essas abordagens, foi tomado como base o trabalho de Hoffnagel (1999), considerado como exemplar para este tema. Demarcando uma perspectiva de análise na sociolinguística interativa, Hoffnagel $(1999$, p.81) comentando Ochs (1993, p. 289), esclarece que:

[...] a identidade social é formada de uma gama de personae sociais que pode ser invocada ou atribuída ao longo da vida, não sendo, portanto, fixa nem categórica, pois um indivíduo pode evidenciar aspectos diferentes como faixa etária, sexo, profissão, etc., dependendo de com quem se está interagindo $[\ldots]$

Neste trabalho, será feita a análise da identidade social de faixa etária na fala de informantes a partir de inquéritos do Projeto Atlas Linguístico do Brasil (Projeto ALiB), com base no uso do item lexical conjuntivite/dor d'olhos, cujos dados foram obtidos por meio do Questionário Semântico Lexical, relativamente ao campo semântico corpo humano, considerando o repertório linguístico de informantes da faixa I (18-30 anos) e faixa II (50-65 anos), em diferentes capitais do país.

O interesse neste trabalho decorre do fato de o léxico possibilitar a observação da leitura que uma comunidade faz de seu contexto e a preservação de parte da memória sócio-histórica e linguístico-cultural da comunidade, além de permitir o registro e a documentação da diversidade lexical e geolinguística do português falado no Brasil. Realizar este trabalho também vem a contribuir para o objetivo mais amplo do Projeto ALiB no que se refere à realização da descrição da realidade linguística do Brasil, no que tange à língua portuguesa, com enfoque prioritário na identificação das diferenças diatópicas e léxico-semânticas, consideradas na perspectiva da geolinguística.

\section{O LÉXICO E A REVELAÇÃO DA IDENTIDADE SOCIAL DE FAIXA ETÁRIA}

Conforme Preti (1991, p. 75), a linguagem dos indivíduos de faixa etária mais avançada apresenta marcas específicas que podem ser vislumbradas nos campos prosódico, sintático, léxico e, sobretudo, discursivo ou conversacional. É justamente nesses últimos campos léxico, discursivo ou conversacional - que será evidenciado o estudo da categoria tempo no discurso dos idosos.

Considerando-se a questão do discurso na perspectiva da faixa etária, é possível afirmar que a linguagem dos idosos pode ser estudada em três perspectivas que mantêm pontos de ligação e não são estáticas: a de caráter cultural, social e psicológico individual. Na perspectiva de caráter cultural, existe a concepção de que os idosos devem ter um papel específico na sociedade em que vivem, de acordo com a tradição cultural a que pertencem; na segunda perspectiva, a de caráter social, há a visão de que a sociedade possui uma postura em relação aos idosos e, de acordo com ela, processam-se as relações sociais entre os idosos e os demais grupos etários; e por último, na perspectiva de caráter psicológico individual, encontramos a ideia de que uma pessoa é tão velha quanto imagina ser. 
Em geral, pode-se dizer que o levantamento das características peculiares à fala das pessoas mais maduras, nos diversos níveis de análise, mostra que as diferenças básicas entre essa linguagem e a dos falantes mais jovens residem muito mais na intensificação das características comuns a ambos, do que propriamente nos traços específicos.

Conforme procura demonstrar Preti (1991, p. 102), a linguagem dos idosos apresenta interferência de fatores naturais, psicofísicos (maior lentidão das reações na comunicação ativa ou receptiva, os problemas de audição e memória) e a outros de natureza sociocultural, como a situação estigmatizada dos velhos na sociedade contemporânea, o que lhes acarreta uma insegurança manifestada em todos os atos de sua vida e, muito particularmente, no seu discurso. Mas essas variações dos processos de repetição e as autocorreções - que interferem na fluência do discurso de pessoas mais velhas - são mecanismos estratégicos que elas utilizam para compensar problemas de disfluência que ocorrem ao nível prosódico e para os quais esses falantes não têm solução; assim, tais recursos permitem aos idosos sustentar o andamento da conversa, isto é, apesar de tudo, seu discurso é levado adiante.

As informações sobre o passado, que transparecem constantemente no discurso dos idosos, muitas vezes, são expressas por um léxico em que aparecem vocábulos, formas de tratamento (um dos índices sociolinguísticos mais expressivos, para evocar as relações sociais entre falante/ouvinte), expressões formulaicas (frases-feitas, provérbios, refrões, expressões que, muitas vezes, remontam à sua infância e a melodia e a rima que, não raro, as acompanham, favorecem a permanência na memória) relacionados com sua época.

Embora haja algumas marcas lexicais do tempo, na fala das pessoas mais velhas especialmente, é preciso reconhecer que nem por isso essa linguagem se tornou ininteligível aos mais jovens, mesmo porque os próprios idosos se encarregam de buscar artifícios para explicar os arcaísmos, as expressões formulaicas fora de uso, a gíria de seu tempo. E são esses artifícios que constituem precisamente as marcas mais expressivas da linguagem desse grupo social.

Nessa perspectiva, Isquerdo (1996, p.93) atesta que o léxico de uma língua tem uma relação muito forte com a história cultural da comunidade, pois registra as distintas mutações que aconteceram na sociedade, afinal, como "qualquer sistema léxico é a somatória de toda a experiência acumulada de uma sociedade e do acervo da sua cultura através das idades" (BIDERMAN, 2011, p. 179).

Sobre esse aspecto linguístico, Isquerdo (2003, p. 178) apresenta que

[...] o conjunto de vocábulos que integra o universo lexical de uma língua, por reproduzir a visão de mundo, o patrimônio cultural dos falantes e por testemunhar a vida, a história e a cultura de um grupo em diferentes fases de sua história, fornece marcas da identidade desse grupo. A forma de usar a língua, particularmente a de escolher as palavras, revela aspectos da maneira de pensar e de agir de um indivíduo/grupo, além de fornecer índices da origem geográfica e da classe social do falante.

É justamente no sentido de valorizarem seu tempo, ou de se mostrarem integrados na sociedade em que vivem, que as pessoas mais velhas escolhem com habilidade o inusitado de suas narrativas e avaliam os pormenores de suas narrativas em função das necessidades da 
interação verbal, considerando os próprios valores e os do ouvinte ou audiência. Enfim, nos esclarece Preti (1991) que, sendo um artifício que se vale fundamentalmente da categoria tempo, as narrativas demonstram o quanto a vida dos falantes mais velhos permanece centrada no passado. Buscando no arquivo da memória fatos para ilustrarem suas ideias, os "idosos" vão acumulando uma preciosa documentação da longa "viagem no tempo" a que costumam entregar-se durante a conversação, denunciando, também, através da utilização de itens lexicais, a sua identidade social de faixa etária.

\section{OS DADOS DO PROJETO ALIB NA PERSPECTIVA DA FAIXA ETÁRIA}

O cenário da pesquisa é um recorte da rede de pontos do Projeto ALiB, um empreendimento de grande amplitude, de caráter nacional, em desenvolvimento, que tem por meta a realização de um atlas geral no Brasil no que diz respeito à língua portuguesa, desejo que permeia a atividade dialetal no Brasil, desde começo do século XX e ganha destaque nesse final/começo de milênio, a partir de iniciativa de um grupo de pesquisadores do Instituto de Letras da Universidade Federal da Bahia e de outras universidades.

A ideia do Atlas Linguístico do Brasil foi retomada por ocasião do Seminário Nacional Caminhos e Perspectivas para a Geolinguística no Brasil, realizado em Salvador, na Universidade Federal da Bahia, em novembro de 1996, com a participação de dialetólogos brasileiros e do Diretor do ALiR (Atlas Linguistique Roman), Prof. Michel Contini (Genoble). Naquela ocasião foi criado um Comitê Nacional, integrado pelos autores dos cinco atlas linguísticos regionais já publicados e por um representante dos atlas em andamento. São eles: os Professores Suzana Alice Marcelino da Silva Cardoso (UFBA), que preside o Comitê, Jacyra Andrade Mota (UFBA), Maria do Socorro Silva de Aragão (UFPB), Mário Roberto Lobuglio Zágari (UFJF), Vanderci de Andrade Aguilera (UEL) e Walter Koch, representando os atlas em andamento ${ }^{1}$.

O Projeto ALiB fundamenta-se nos princípios gerais da Geolinguística contemporânea, priorizando a variação espacial ou diatópica e atento às implicações de natureza social que não se pode, no estudo da língua, deixar de considerar. Assim, o Projeto ALiB objetiva descrever o português falado no Brasil com base em dados coletados em 250 pontos, representativos de todas as regiões, e recolhidos, in loco, a 1.100 informantes, distribuídos equitativamente por duas faixas etárias - 18 a 30 anos e 50 a 65 anos - , pelos dois gêneros e, nas capitais de Estado, em número de 25 (as capitais Palmas, Estado de Tocantins, e Brasília, Distrito Federal, se excluem por questões metodológicas em virtude de serem cidades recém-criadas), por dois níveis de escolaridade - fundamental e universitário ficando os demais pontos da rede com apenas informantes do nível fundamental.

\footnotetext{
${ }^{1}$ Atualmente, o Comitê Nacional do Projeto ALiB é constituído pelos professores Suzana Alice Cardoso (Presidente), Jacyra Andrade Mota (Diretora-Executiva), ambas da UFBA, e os diretores científicos Abdelhak Razky (UFPA), Ana Paula Rocha (UFOP), Aparecida Negri Isquerdo (UFMS), Cléo Altenhofen (UFRGS), Felício Wessling Margotti (UFSC), Maria do Socorro Aragão (UFPB/UFC) e Vanderci de Andrade Aguilera (UEL).
} 
Ao se atingir, em 2013, a totalidade da recolha de dados da rede programada, algumas considerações iniciais já podem ser feitas sobre áreas dialetais brasileiras. Nesse sentido, apresentam-se neste artigo, de forma ilustrativa, resultados que mostram a diversidade de usos vinculada a áreas específicas, mas também relacionada a fatores sociais.

Dessa forma, para este trabalho, serão considerados fatos relacionados à diversidade diatópica e à diferenciação diageracional, não se incluindo, para esse momento, a diferenciação diagenérica ou diastrática, embora, no levantamento e análise dos dados, essas variáveis sociais tenham sido controladas sistematicamente.

Os resultados que se apresentam fundamentam-se em levantamentos no corpus do Projeto ALiB, especificamente nas capitais de Estados, conforme pode ser visualizado no quadro a seguir.

Quadro 1 As denominações para inflamação dos olhos nas capitais do Brasil numa perspectiva diageracional

\begin{tabular}{|c|c|c|c|c|}
\hline \multirow[t]{2}{*}{ Localidade } & \multicolumn{2}{|c|}{ Faixa Etária 1} & \multicolumn{2}{|l|}{ Faixa Etária 2} \\
\hline & Utiliza & Conhece & Utiliza & Conhece \\
\hline Macapá & Conjuntivite & & Dor-d'olhos & Conjuntivite \\
\hline Boa Vista & Conjuntivite & & Dor-d'olhos & $\begin{array}{l}\text { Conjuntivite } \\
\text { Outras variantes }\end{array}$ \\
\hline Manaus & Conjuntivite & & Conjuntivite & \\
\hline Belém & Conjuntivite & & Dor-d'olhos & \\
\hline Rio Branco & Conjuntivite & & Dor-d'olhos & Conjuntivite \\
\hline Porto Velho & Conjuntivite & & Dor-d'olhos & Conjuntivite \\
\hline São Luís & Conjuntivite & & Dor-d'olhos & $\begin{array}{l}\text { Conjuntivite } \\
\text { Outras variantes }\end{array}$ \\
\hline Teresina & $\begin{array}{l}\text { Conjuntivite } \\
\text { Outras variantes }\end{array}$ & Outras variantes & Conjuntivite & Outras variantes \\
\hline Fortaleza & Conjuntivite & & Dor-d'olhos & Conjuntivite \\
\hline Natal & Conjuntivite & & Conjuntivite & Outras variantes \\
\hline João Pessoa & Conjuntivite & & Dor-d'olhos & $\begin{array}{l}\text { Conjuntivite } \\
\text { Outras variantes }\end{array}$ \\
\hline Recife & Conjuntivite & & Outras variantes & \\
\hline Maceió & Conjuntivite & & Outras variantes & \\
\hline Aracaju & Conjuntivite & & Dor-d'olhos & Conjuntivite \\
\hline Salvador & Conjuntivite & & Conjuntivite & \\
\hline Cuiabá & Conjuntivite & Dor-d'olhos & $\begin{array}{l}\text { Conjuntivite e Dor- } \\
\text { d'olhos }\end{array}$ & Conjuntivite \\
\hline Campo Grande & Conjuntivite & Dor-d'olhos & $\begin{array}{l}\text { Conjuntivite e Dor- } \\
\text { d'olhos }\end{array}$ & \\
\hline Goiânia & Conjuntivite & Outras variantes & Conjuntivite & Outras variantes \\
\hline Belo Horizonte & Conjuntivite & & Conjuntivite & Outras variantes \\
\hline São Paulo & Conjuntivite & & Conjuntivite & Outras variantes \\
\hline Vitória & Conjuntivite & & $\begin{array}{l}\text { Conjuntivite e Dor- } \\
\text { d'olhos }\end{array}$ & Conjuntivite \\
\hline Rio de Janeiro & Conjuntivite & & Conjuntivite & \\
\hline Curitiba & Conjuntivite & & Dor-d'olhos & Conjuntivite \\
\hline Florianópolis & Conjuntivite & & Dor-d'olhos & Conjuntivite \\
\hline Porto Alegre & Conjuntivite & & Conjuntivite & \\
\hline
\end{tabular}


Como mostra o Quadro 1, a questão 95 do questionário semântico-lexical (QSL) apresentou designações, nas capitais do Brasil, que foram agrupadas em três categorias, a saber: a) conjuntivite; b) dor d'olhos e c) outras variantes (sapatão, gripe nas vistas, bonitinho, constipação, gripe na cabeça, inflamação, doença ocular e olho inflamado). Dessas designações, apenas conjuntivite é comum às capitais pesquisadas, dor d'olhos está no Nordeste quase todo, em duas capitais do Centro Oeste e mais em Vitória, Curitiba e Florianópolis. As demais formas encontram-se distribuídas entre as capitais.

No que se refere ao aspecto diageracional, o Gráfico 1 apresenta as denominações para inflamação dos olhos nas capitais do Brasil dos informantes das faixas etárias 1 e 2 .

Gráfico 1 Denominações dos informantes das faixas etárias 1 e 2 para inflamação dos olhos

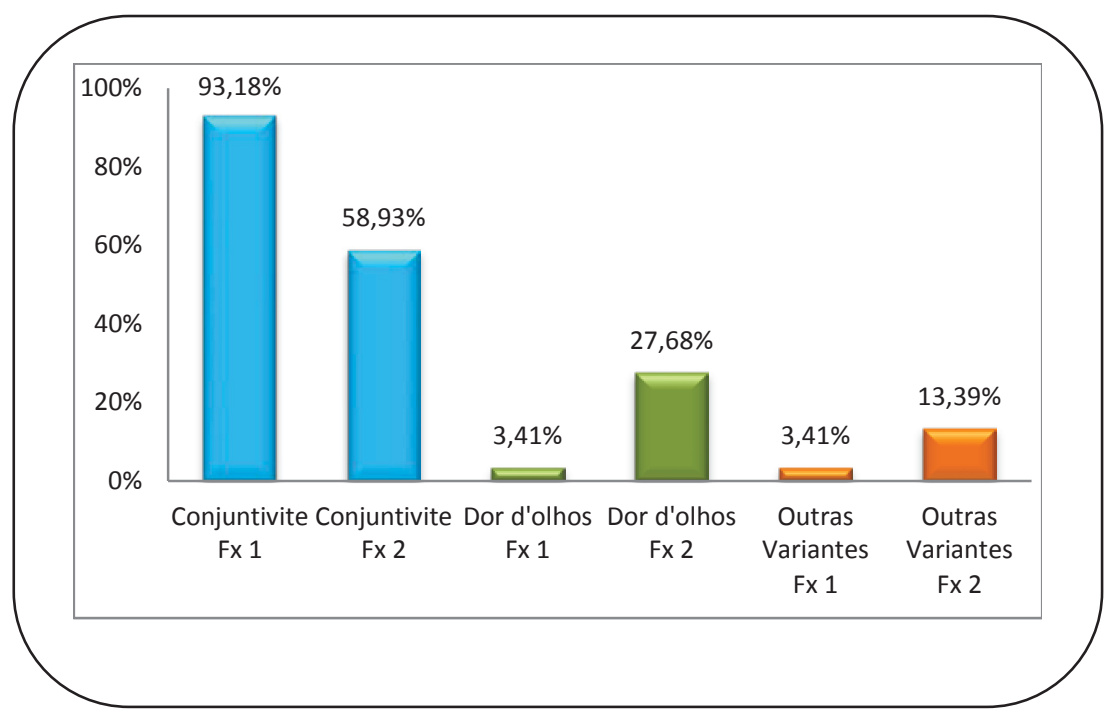

Conforme é possível visualizar no gráfico, a variante lexical dor d'olho $(27,68 \%)$ é sinalizada no discurso dos informantes como uma variante típica de informantes mais velhos, apenas ocorrendo em 3,41\% na fala da faixa 1 . A motivação dessa designação está na dor que se sente nos olhos, por isso "dor de olho", quando se contrai essa inflamação. A designação conjuntivite, com $93,18 \%$ na faixa 1 e $58,93 \%$ para faixa 2 , por sua vez, é apontada nos exemplos como a maneira mais atual de falar, conforme demonstra o exemplo 1.

\section{Exemplo 1}

INQ.- Como se chama aquela inflamação no olho que faz com que o olho fique vermelho, amanheça grudado?

INF.- Conjuntivite.

INQ.- Mas o nome popular?

INF.- Mas, antigo também, as pessoas chamam dor d'olhos. 
INQ.- Esse é o mais comum, não é?

INF.- Não, conjuntivite é o mais comum.

INQ.- Se eu perguntar pras pessoas mais da periferia?

INF.- Olha, talvez não... eu acho que sim, eu acho que a ideia do dor d'olhos é uma ideia mais de um, de um, um traço de idade do que um traço de, de nível sócio-econômico. (Vitória, Mulher, Faixa 2, Nível Superior)

Esse exemplo revela como o discurso se configura como um modo de ação, como também um modo de representação. Nesse sentido, o discurso é uma prática de significação do mundo, que focaliza, dentre os aspectos relativos aos efeitos construtivos, a construção, manutenção e projeção da identidade social de faixa etária da informante, por meio da seleção lexical diageracional, mostrando a noção de temporalidade em que o discurso foi produzido.

Assim, o papel da memória é tradicionalmente valorizado entre os mais velhos; suas lembranças constituem patrimônio coletivo, expresso e revivido permanentemente no contato com novas gerações, sejam crianças ou adultos, inclusive, chegando a opor as designações lexicais do passado (dor d'olhos) e do presente (conjuntivite) ou, ainda, revelando a consciência de que antigamente se falava de forma diferente. Por meio dessa oposição e dessa consciência, existe a revelação da identidade social conceituada por Hoffnagel (1999) como constituída por uma gama de personae sociais que pode ser invocada ou atribuída ao longo da vida, não sendo, portanto, fixa uma vez que um indivíduo pode evidenciar aspectos diferentes como faixa etária, sexo, profissão etc., dependendo de com quem se está interagindo. No caso em questão, o que se percebe é a identidade social de faixa etária, como mostra o exemplo 2.

\section{Exemplo 2}

INQ.- Agora, aquela inflamação que dá no olho, que o olho nasce grudado...

INF.- Bom, eu conheci...

INQ.- Amanhece. Nasce não, amanhece grudado?

CIR.- Grudado.

INF.- Conheci, é... como era? Não, não, era doença, doença da vista. Doença, dor d'olho, dor d'olho, dor d'olho, que dá, fica com a vista colada, dor d'olho, eu tô com dor d'olho, dor d'olho na vista, dor d'olho. (Florianópolis, Homem, Faixa 2, Nível Fundamental)

No exemplo 3, além do dado diageracional, é possível verificar um caso que aponta para o fato de as ciências não transitarem por caminhos com limites rígidos, permitindo diálogos com outras áreas do saber.

\section{Exemplo 3}

INQ.- Há uma inflamação seu M. que dá no olho e faz com que ele fique vermelho e amanheça grudado... 
INF.- Ah tem o... de primeiro tinha muito eu já teve isso, é dor d'olho.

INQ.- Isso!

INF.- O dor d'olho e tem e aí tem... tem a conjuntivite também né como se chama agora? Eu também já teve esse conjuntivite... esse... esse dor d'olho é terrível, eu tive muito isso.

INQ.- Dor d'olho né?

INF.- Ah dói demais e o olho fica ardendo e fica vermelho parece que vai sair até sangue.

INQ.- É.

INF.- Eu curava muito, nesse tempo... no tempo de criança não tinha nem... remédio podia ser que tinha remédio mas não podia comprar que era muito pobre né?

INQ.- É.

INF.- Aí minha mãe usava de tirar folha de... fedegoso.

INQ.- Ah!

INF.- Pra tirar o sumo, batia ele depois com... botava um poco de água numa vasilha, batia bem mesmo, socava bem ele, depois torcia num pano pra tirar o suco da folha do... do fedegoso pra escaldar o olho.

INQ.- Ah.

INF.- E com isso aí melhorava.

INQ.- Olha só que interessante né?

INF.- E... ou então também botava limão, aquele limãozinho... limão é... limão caipira nosso, não sei se a senhora conhece.

INQ.- Conheço.

INF.- Limão caipira daquele pequenininho assim, daquele bem verdinho, corta ele em cruz, aí fazia assim um tipo simpatia, né?

INQ.- Ahã.

INF.- Aí um lado do gomo, que fica quatro gomo partido em cruz, fica quatro gomo né? Quatro pedaço, aí um pedaço joga pro lado do sol poente, do lado que o sol entra né?

INQ.- Huhum.

INF.- E outros três, as outras três partes põe dentro d'uma água bem limpa, fervida, né? Ferve ela, se é com água assim bruta como era no caso nosso lá lá num tinha filtro né? Era água de 
poço, de cacimba, essas coisa né? Aí, então, fervia aquela água deixava esfriar pra pôr o limão na água pra escaldar o olho, também é bom.

INQ.- É, bom também.

INF.- É, mas o limão bem verdinho, né? Bem verde.

INQ.- Certo. (Cuiabá, Homem, Faixa 2, Nível Fundamental)

O discurso desse informante, ao descrever um remédio caseiro para o tratamento da conjuntivite, exemplifica as interfaces da Dialetologia com outros ramos do conhecimento, como já apontou Cardoso (2006, p. 98): “[...] o conhecimento científico é, na realidade, uma grande teia, tecida com fios diversos, na qual se põem em destaque ora um, ora outro desses 'fios' que se podem identificar $[\ldots]$ '.

Em face disso, verifica-se que, no exemplo 3, existem marcas específicas no campo lexical, discursivo ou conversacional, como expõe Preti (1991, p. 75), que marcam o discurso de faixas etárias mais avançadas, além de ser possível observar a projeção da identidade social de faixa etária, através da seleção lexical realizada pelo informante, evidenciando uma conexão entre a Dialetologia e outros ramos do conhecimento, neste caso, a área da saúde.

É precisamente essa preocupação simultânea com o "dizer" e com o "que dizer" que vai evidenciar, no texto falado, uma série de marcas responsáveis pela caracterização específica de sua formulação, entre as quais as que sinalizam o trabalho de seleção lexical por meio de itens lexicais denunciadores da faixa etária do informante.

\section{CONSIDERAÇÕES FINAIS}

O corpus do ALiB contempla a documentação da diversidade lexical do português falado no Brasil, conforme os princípios da Teoria Social do Discurso, que tem contribuições a dar na análise de variantes lexicais diageracionais, e da Geolinguística Pluridimensional, em que o registro segue os parâmetros diatópicos, diageracionais, diagenéricos e diastráticos. Em particular, no que diz respeito às denominações que recebe conjuntivite podem-se fazer algumas considerações preliminares:

a) o discurso analisado dos informantes do Projeto ALiB reflete uma prática de significação do mundo, constituindo e construindo o mundo em significado que possibilita a visualização da construção, manutenção e projeção da identidade social de faixa etária.

b) as designações enfocadas representam uma variação que possibilita a visualização da diversidade lexical e geolinguística do português falado no Brasil;

c) a temática da comparação passado vs.presente está na linguagem dos informantes de faixa etária mais avançada, evidenciado-se na seleção lexical desses informantes como demonstra a estrutura dor d'olho. 
O trabalho procurou mostrar como as lexias trazem, na fala dos informantes, as marcas do contexto em que se encontram inseridas, fornecendo subsídios para o registro da diversidade da língua portuguesa.

\section{REFERÊNCIAS}

BIDERMAN, M. T. C. Teoria linguística: teoria lexical e linguística computacional. São Paulo: Martins Fontes, 2001.

CARDOSO, S. A. M. Dialectologia e ensino-aprendizagem da língua materna. In: MOTA, J. A.; CARDOSO, S. A. M. (Orgs.). Documentos 2. Salvador: Quarteto, 2006, p. 97-107.

COMITÊ NACIONAL DO PROJETO ALiB: Atlas Linguístico do Brasil. Questionários. Londrina: UEL, 2001.

FAIRCLOUGH, N. Discurso e mudança social. Brasília: Editora Universidade de Brasília, 2001.

HOFFNAGEL, J. C. A emergência de identidades na atividade discursiva falada e escrita. In: MOURA, D. (Org.). Os múltiplos usos da língua. Maceió: [s.n.], 1999, p. 80-91.

ISQUERDO, A. N. O fato lingüístico como recorte da realidade sócio-cultural. 1996. 409 f. Tese (Doutorado em Letras) - Faculdade de Letras, Universidade Estadual Paulista, Araracuara, 1996.

Léxico em tempo e espaço: a questão dos regionalismos. In: MARIN, J. R.; VASCONCELOS, C. A. de. (Orgs.). História, região e identidades. Campo Grande: Editora da UFMS, 2003, p. 165-181.

OCHS, E. Linguistic resoursces for socializaing humanity. In: GUMPERZ, J.; LEVINSON, S. (Orgs.). Rethinking linguistic relativity. Cambridge: Cambridge University Press 1993. p. 407-437.

PRETI, D. A linguagem dos idosos. São Paulo: Contexto, 1991.

Recebido: 27/05/2013

Aceito: 30/08/2013 